\title{
ANALISIS BAHAN BAKAR ALTERNATIF KOMPOSIT BIOBRIKET DARI ECENG GONDOK DENGAN PEREKAT KOTORAN SAPI
}

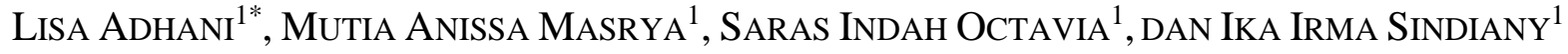 \\ ${ }^{1}$ Program Studi Teknik Kimia, Fakultas Teknik, Universitas Bhayangkara Jakarta Raya \\ Jl. Raya Perjuangan Marga Mulya, Bekasi Utara, 17143 \\ *alamat email korespondensi: lisa.adhani@dsn.ubharajaya.ac.id
}

\begin{tabular}{l} 
Informasi Artikel \\
\hline Riwayat Naskah : \\
Diterima pada 25 \\
November 2019 \\
Diterima setelah \\
direvisi pada 28 \\
Desember 2019 \\
Diterbitkan pada 30 \\
Desember 2019
\end{tabular}

Kata Kunci: biomassa; Eichhornia crassipes; biobriket; kotoran sapi; sem

Keywords: biomass; Eichhornia crassipes; biobriquette; cow dung; sem

\begin{abstract}
Abstrak/Abstract
Energi terbarukan merupakan energi alternatif yang menjadi isu energi teratas, mengingat menipisnya persediaan bahan bakar bumi (tak terbarukan). Biomassa adalah adalah energi alternatif yang menarik untuk dikembangkan saat ini, terutama di Indonesia yang dikenal sebagai negeri agraris dan disebut sebagai negeri biodiversitas. Eceng gondok (Eichhornia crassipes) merupakan satu biomassa yang berpotensi sebagai bahan bakar alternatif. Tanaman ini banyak hidup di daerah perairan Indonesia seperti sungai dan rawa-rawa. Pertumbuhan eceng gondok sangat cepat sehingga jumlahnya seringkali melimpah dan tak terkendali. Tanpa adanya pantauan yang baik, membuat tanaman ini menjadi pengganggu habitat disekitarnya. Sehingga memperburuk estetika dan menimbulkan bau. Penelitian ini memanfaatkan eceng gondok menjadi bahan bakar alternatif dengan campuran kotoran sapi sebagai bahan perekatnya. Eceng gondok di manfaatkan menjadi biobriket dengan proses karbonasi anaerob pada temperature $400^{\circ} \mathrm{C}$. Proses pembuatan biobriket tersebut dilakukan dengan variasi komposisi antara eceng gondok dan kotoran sapi dengan persentase $30 \%$, $50 \%$, dan $70 \%$. Berdasarkan hasil penelitian, biobriket dengan komposisi kotoran sapi $70 \%$ adalah biobriket terbaik jika mengacu pada SNI 01-6235-2000 yaitu memiliki kadar air $0,0435 \%$, kadar abu $0,47 \%$ dan nilai kalor sebesar $4715 \mathrm{kal} /$ gram. Uji SEM (Scanning Electron Microscope) memperkuat kesimpulan dengan menggambarkan morfologi agglomerasi yang teratur sehingga dapat dikatakan membuat rongga pada bagian tengah dari briket, sehingga luas permukaan briket lebih besar yang menyebabkan laju pembakaran lebih tinggi.
\end{abstract}

\begin{abstract}
Renewable energy is an alternative energy which is the top energy issue, given the depletion of (non-renewable) fuel supplies. Biomass is an interesting alternative energy to be developed at this time, especially in Indonesia which is known as an agrarian country and is called a biodiversity country. Water hyacinth (Eichhornia crassipes) is a biomass that has the potential as an alternative fuel. This plant lives in many Indonesian waters such as rivers and swamps. The growth of water hyacinth is so fast that the amount is often abundant and out of control. Without good monitoring, this plant will make a disturbance to the surrounding habitat. Thus worsening the aesthetics and odor. This study utilizes water hyacinth as an alternative fuel with a mixture of cow dung as an adhesive. Water hyacinth is utilized as biobriquette with anaerobic carbonation process at a temperature of $400 \circ \mathrm{C}$. The process of making biobriquette is done by varying the composition between water hyacinth and cow dung with a percentage of 30\%, 50\%, and 70\%. Based on the results of the study, biobriquettes with a composition of $70 \%$ cow dung are the best biobriquettes when referring to SNI 01-6235-2000 which has a moisture content of 0.0435\%, ash content of 0.47\% and a calorific value of $4715 \mathrm{cal} / \mathrm{gram}$. The SEM (Scanning Electron Microscope) test strengthens the conclusion by describing the morphology of the regular agglomeration so that it can be said to make a cavity in the middle of the briquette, thereby causing the briquette's surface area to be larger so that the combustion rate is higher.
\end{abstract}

\section{PENDAHULUAN}

"No Energy, No life" slogan ini begitu populer saat ini. Hal ini menyatakan bahwa energi sebagai kebutuhan pokok dalam hidup manusia, terutama di era modern ini. Namun, saat ini krisis energi menjadi perbincangan teratas di dunia. Hal ini memberikan dampak yang sangat besar bagi masyarakat Indonesia, karena sebagian besar masyarakat Indonesia masih bergantung pada bahan bakar Fosil. Menipisnya bahan bakar fosil harus segera diimbangi dengan penyediaan energi alternatif yang dapat diperbaharui, melimpah bahan bakunya dan murah harganya sehingga dapat terjangkau oleh masyarakat luas [1]. Terdapat 
beberapa jenis sumber energi alternatif yang dapat dikembangkan, diantaranya adalah energi biomassa. Peranan biomassa ini terus bertambah seiring perkembangan teknologi konversi. Pemanfaatan biomassa yang semakin luas membawa peningkatan kuantitas dan kualitas produk bioenergi yang setara dengan standar bahan bakar konvensional. Satu diantara pemanfaatan biomassa yang sederhana adalah pembuatan biobriket. Biobriket adalah bahan bakar biomassa yang digunakan sebagai pengganti arang dan batu bara.

Biobriket dapat dihasilkan dari berbagai limbah padat, salah satunya adalah eceng gondok [2]. Di Indonesia eceng gondok merupakan tumbuhan air yang melimpah jumlahnya, karena jumlahnya yang melimpah dan pertumbuhannya yang cepat maka eceng gondok dianggap sebagai tumbuhan pengganggu perairan. Oleh karena itu dengan mengubah limbah eceng gondok menjadi biobriket, maka akan meningkatkan nilai ekonomis bahan tersebut. Pada penelitian ini, eceng gondok dipilih sebagai bahan biomassa dengan campuran kotoran sapi sebagai perekat dengan perbandingan tertentu, yang kemudian dibuat menjadi biobriket. Biobriket merupakan biomassa berbentuk padat yang dapat dijadikan bahan bakar. Wujud padat ini dilakukan melalui proses pemadatan atau densification, hal ini dimaksudkan agar terjadi peningkatan atau pertambahan kuantitas energi per satuan volume.

Jenis perekat sangat menentukan kualitas dari biobriket. Terdapat dua golongan perekat dalam pembuatan biobriket, yaitu perekat yang berasap dan perekat yang kurang berasap. Golongan perekat berasap diantaranya golongan tar, pitch, clay, dan molases, sedangkan yang tidak berasap yaitu golongan pati, dekstrin, dan tepung beras [3]. Telah diketahui bahwa pemakaian golongan tar, pitch, clay, dan molases sebagai bahan perekat akan menghasilkan biobriket yang berkekuatan tinggi tetapi mengeluarkan banyak asap jika dibakar karena adanya komponen yang mudah menguap. Sedangkan bahan perekat dari golongan pati, dekstrin, dan tepung beras akan menghasilkan biobriket yang tidak berasap dan tahan lama tetapi nilai kalornya rendah[4]. Bahan perekat dari tumbuh-tumbuhan seperti pati (tapioka) memiliki keuntungan dimana jumlah perekat yang dibutuhkan untuk jenis ini jauh lebih sedikit dibandingkan dengan bahan perekat hidrokarbon [3]. Namun bahan perekat tapioka memiliki kelemahan karena memiliki daya serap yang tinggi terhadap air diudara, sehingga menyebabkan sulitnya dalam penyimpanan, terutama diwilayah yang memiliki kelembaman yang tinggi. Kadar air yang tinggi dalam biobriket menyebabkan kebutuhan energy yang tinggi untuk menguapkan air dan kadang-kadang briket terbelah menjadi potongan potongan kecil pada tingkat pembakaran rendah, sehingga lebih sedikit panas yang dihasilkan oleh pembakaran biobriket, akibatnya asap yang dihasilkan akan banyak [5 - 7].

Asap juga bisa disebabkan oleh kadar abu yang tinggi. Abu adalah komponen biomassa yang tidak mudah terbakar sehingga mempengaruhi proses transfer panas ke permukaan biobriket. Difusi oksigen ke permukaan biobriket selama proses pembakaran juga terganggu dengan kadar abu yang tinggi [5].

Perekat yang baik untuk pembuatan biobriket memiliki spesifikasi karakteristik seperti; mudah terbakar, tidak berasap, murah harganya, memiliki gaya kohesi bila dicampurkan dengan bioarang, memiliki kadar abu yang rendah, mudah didapat dalam jumlah banyak, tidak mengeluarkan bau, tidak beracun dan tidak berbahaya [8].

\section{EKSPERIMEN}

Penelitian ini memanfaatkan tanaman eceng gondok menjadi biobriket dengan proses karbonasi anaerob pada temperature $400^{\circ} \mathrm{C}$ dan perekat kotoran sapi. Kotoran sapi yang dipakai divariasikan dengan persentase $30 \%, 50 \%$, dan $70 \%$. Karim, M.A dkk pernah melakukan penelitian membuat biobriket dari eceng gondok dengan perekat tepung tapioca [9].

\section{Material}

Eceng gondok adalah bahan yang digunakan dalam penelitian ini. Eceng Gondok didapat dari sungai Kalimalang, Bekasi dan Kotoran Sapi yang diperoleh dari seternakan sapi di daerah Tambun Bekasi. Kotoran sapi yang digunakan adalah kotoran sapi yang masih baru, sehingga dapat berfungsi sebagai perekat.

\section{Instrumentasi}

SEM (scanning Electron Microscopy) FEI; Type Inspect-S50. Gold-ISO1716 Bom kalorimeter

\section{Prosedur}

\section{Proses Karbonasi}

Proses ini dilakukan untuk mengubah eceng gondok menjadi arang. Eceng gondok dibersihkan menggunakan air bersih agar terlepas dari 
kotorannya. Eceng gondok yang telah bersih kemudian di potong $( \pm 3 \mathrm{~cm})$ dan dikeringkan selama 2 hari dibawah sinar matahari. Hal ini dimaksudkan agar kandungan air dalam eceng gondok berkurang. Proses Karbonasi atau pengarangan dilakukan menggunakan furnace dengan Temperatur $400^{\circ} \mathrm{C}$ selama 1 jam [9].

\section{Proses Pembuatan Biobriket}

Arang hasil Karbonasi eceng gondok dihaluskan dengan lumpang, kemudian diayak dengan ukuran 80 mesh. Arang yang telah diayak kemudian ditambahkan kotoran sapi sebagai bahan perekat dengan komposisi 30\%, 50\%, dan $70 \%$ dari berat arang, kemudian campurkan hingga homogen. Beri label setiap campuran (pembuatan dirancang oleh tim peneliti sebagai bagaian dari variable penelitian).

\section{Proses Pencetakan Biobriket}

Bahan-bahan yang telah dicampur dimasukkan ke alat pencetak, ditekan untuk dijadikan biobriket. Selanjutnya biobriket dikeringkan menggunakan oven pada temperatur $80^{\circ} \mathrm{C}$ selama $10 \mathrm{jam}$. Biobriket dikeluarkan dari oven lalu dibiarkan hingga dingin. Biobriket siap diuji kualitas [9].

\section{Metode Analisis}

Perhitungan Kadar Air menggunakan rumus sebagai berikut :

SNI 01-6235-2000

Kadar Air $(\%)=\mathrm{W}_{1} / \mathrm{W}_{2} \times 100 \%$

$\mathrm{W} 1=$ Bobot Semula (gr)

W2 $=$ Bobot Setelah Pemanasan (gr)

Perhitungan Kadar Abu menggunakan rumus sebagai berikut :

SNI 01-6235-2000

Kadar Abu (\%) $=\mathrm{W}_{1} / \mathrm{W}_{2} \times 100 \%$

$\mathrm{W} 1=$ Bobot Setelah Pemanasan $(\mathrm{gr})$

$\mathrm{W} 2=$ Bobot Awal (gr)

\section{HASIL DAN PEMBAHASAN}

\section{Analisis Kadar Air}

Kadar air adalah salah satu faktor yang harus dipertimbangkan karena memiliki pengaruh terhadap Nilai kalor, semakin tinggi kadar air yang terkandung maka daya pembakaran akan semakin menurun atau biobriket sulit untuk terbakar, serta panas yang dihasilkan sedikit dan akibatnya asap yang dihasilkan pada pembakaran akan banyak.
Berdasarkan hasil penelitian dan pengujian Kadar Air Biobriket Eceng Gondok dan Kotoran Sapi ditunjukkan pada Gambar 1 berikut ini:

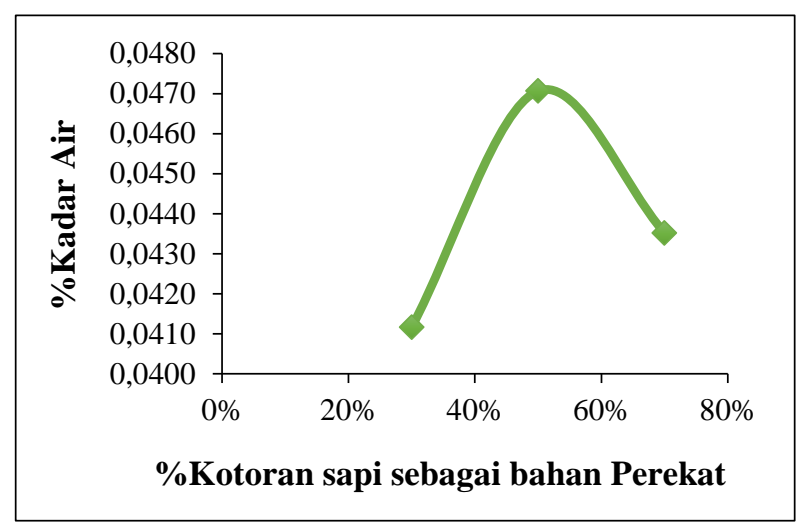

Gambar 1. Hasil Pengujian Kadar Air

Dari Gambar 1 dapat dilihat bahwa kadar air tertinggi terdapat pada biobriket dengan perbandingan komposisi $50 \%$ yaitu $0.0471 \%$ sedangkan, kadar air terendah terdapat pada biobriket dengan komposisi kotoran sapi 30\% yaitu $0.0412 \%$.

Pada komposisi kotoran sapi $70 \%$ biobriket mengandung air $0.0435 \%$, lebih tinggi dari komposisi kotoran sapi $30 \%$ dan lebih rendah dari $50 \%$. Hal ini disebabkan karena eceng gondok memiliki serat yang lebih tinggi dibanding kotoran sapi. Hal ini menyebabkan air tidak mudah terlepas pada proses pengeringan [2].

Jika dilihat dari uji SEM (Gambar 5 di bawah), bahwa serat eceng gondok menyebabkan agglomerasi yang lebih banyak dan menguasai permukaan karena eceng gondok mempunyai bobot molekul yang lebih tinggi dibanding kotoran sapi, sehingga penggumpalan lebih tidak teratur dan memperkecil pori [10]. Hal ini yang dimungkinkannya air terjebak didalam serat eceng gondok yang teragglomerasi.

Maka berdasarkan analisis kadar air dapat dikatakan bahwa komposisi optimum untuk mendapatkan biobriket yang baik adalah pada komposisi perekat 70\% dengan kadar air 0,0435\% masih masuk dalam syarat SNI 01-6235-2000, yaitu kurang dari $8 \%$, dan dapat dikatakan memiliki kualitas yang baik [11].

\section{Analisis Kadar Abu}

Dari Gambar 2 di bawah ini dapat dilihat bahwa nilai kadar abu tertinggi dihasilkan pada biobriket komposisi kotoran sapi 30\%, dan nilai kadar abu terendah dihasilkan pada komposisi 
perekat $70 \%$, artinya adalah semakin banyak kotoran sapi yang terkandung pada biobriket tersebut maka kadar abu yang terkandung semakin rendah, begitupun sebaliknya.

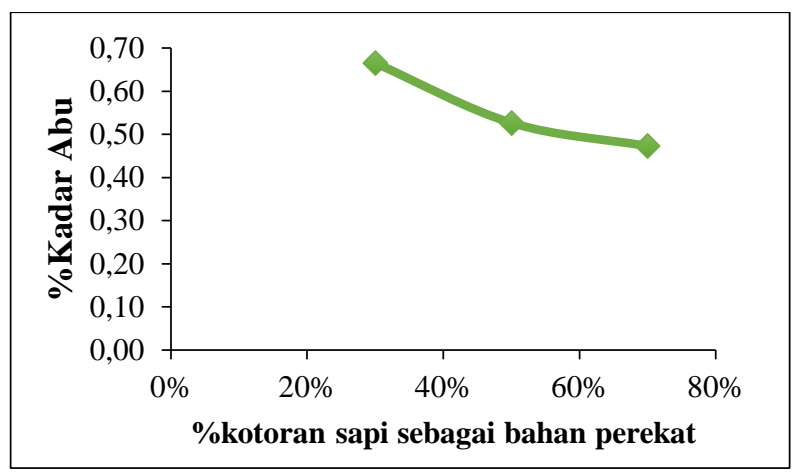

Gambar 2. Hasil Pengujian Kadar Abu

Kadar abu yang terkandung pada biobriket merupakan salah satu hal yang dapat mempengaruhi kualitas biobriket tersebut, karena semakin tinggi kadar abu yang terkandung maka akan menurunkan nilai kalor dari biobriket tersebut [12]. Maka dalam penelitian ini dipilih biobriket komposisi $70 \%$ dengan kadar abu terendah yaitu $0.47 \%$, persentase kadar abu memenuhi SNI 016235-2000 yaitu kurang dari 8\% [11].

Emisi debu yang dihasilkan dari biobriket yang memiliki kadar debu yang tinggi, akan menimbulkan polusi udara. Kadar abu juga akan mempengaruhi volume dan efisiensi pembakaran, semakin rendah kadar abu semakin tinggi efisiensinya. Semakin tinggi kadar abu biobriket, semakin rendah nilai kalorinya [12].

Kadar abu dan kadar air pada biobriket juga mempengaruhi laju pembakaran dan memperkecil polutan [13]. Semakin tinggi kadar air dan kadar abu, akan menyebabkan rendahnya transfer panas ke bagian dalam biobriket dan difusi oksigen ke permukaan biobriket arang selama pembakaran [14].

\section{Analisis Nilai Kalor}

Dari Gambar 3 di bawah ini dapat dilihat nilai kalor tertinggi dihasilkan oleh biobriket dengan komposisi 70\%. Nilai kalor adalah faktor yang sangat berpengaruh pada daya pembakaran biobriket, karena semakin tinggi nilai kalor yang dihasilkan maka daya bakar biobriket yang dihasilkan pun sangat tinggi [15]. Maka dalam penelitian ini nilai kalor adalah faktor yang paling dipertimbangkan dalam pemilihan biobriket yang berkualitas.

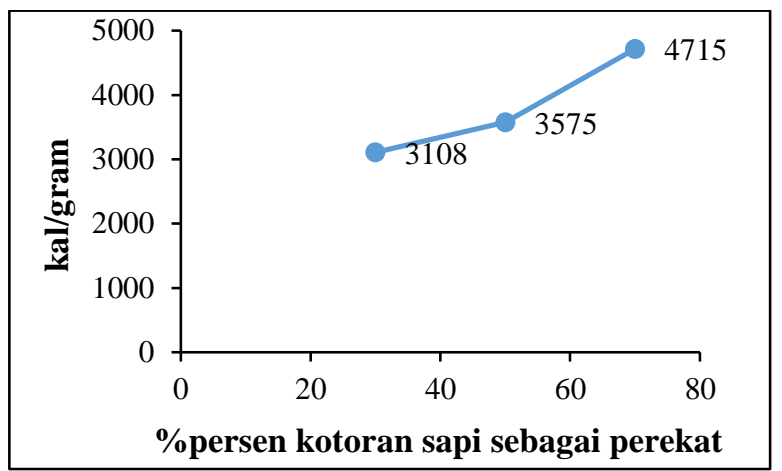

Gambar 3. Hasil Pengujian Nilai Kalor

Dari ketiga sampel tersebut maka biobriket yang dipilih dalam penelitian ini adalah biobriket dengan komposisi $70 \%$ dengan nilai kalor 4715 $\mathrm{kal} / \mathrm{gram}$. Nilai kalor yang dihasilkan belum memenuhi standar SNI 01-6235-2000 nilai kalor minimum adalah $5000 \mathrm{kal} / \mathrm{gram}$, namun dengan selisih yang tidak terlalu besar, dapat dikatakan biobriket yang dihasilkan dapat digunakan sebagai bahan bakar alternatif [16].

\section{Uji Scanning Electron Microscopy}

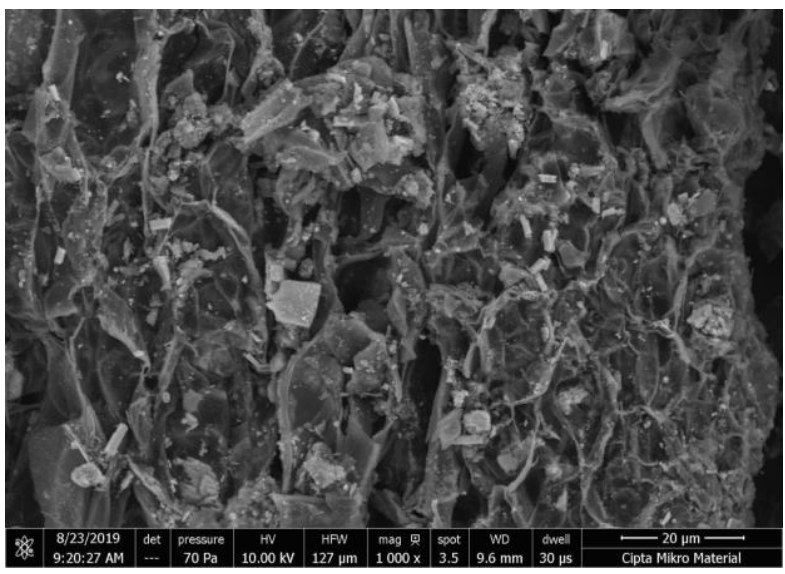

Gambar 4. Hasil SEM pada biobriket eceng gondok dengan perekat kotoran sapi

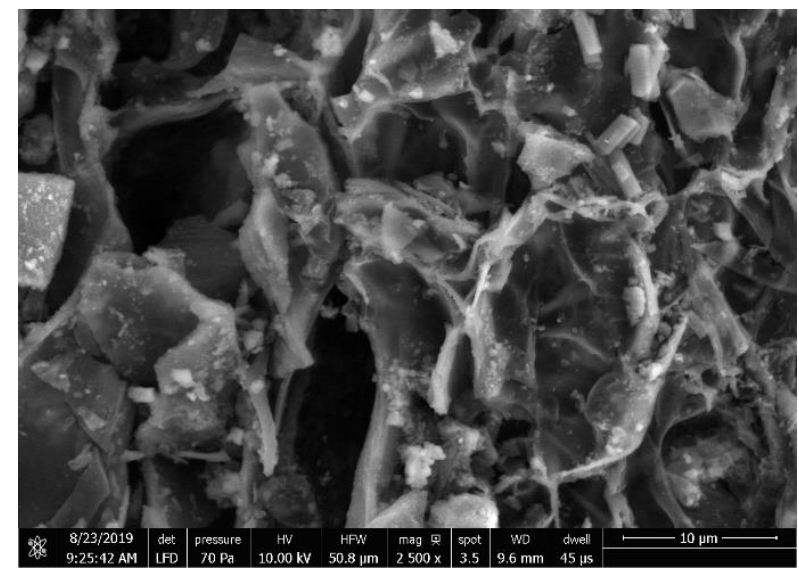

Gambar 5. Hasil SEM pada pembesaran (mag 2500x) 
Dari hasil SEM pada Gambar 4 dan Gambar 5 menunjukkan permukaan yang lebih tinggi berwarna lebih cerah dari permukaan lebih rendah. Hal ini memperlihatkan bahwa backscattered electron memberikan perbedaan berat molekul dari atom-atom yang menyusun permukaan, atom dengan berat molekul tinggi berwarna lebih cerah dari pada atom dengan berat molekul lebih rendah [17]. Eceng gondok memiliki berat molekul lebih berat dibanding kotoran sapi [2], terlihat agglomerasi yang teratur dari serat eceng gondok membuat rongga pada bagian tengah dari briket, hal ini menyebabkan luas permukaan briket lebih besar sehingga menyebabkan laju reaksi semakin tinggi. Hal ini dapat dikatakan biobriket akan mudah terbakar dan menghasilkan kalor yang optimum [18].

\section{SIMPULAN}

Hasil penelitian dan pengujian biobriket eceng gondok dan kotoran sapi dapat disimpulkan bahwa kandungan kotoran sapi yang ditambahkan memberikan pengaruh terhadap kadar air, kadar abu dan nilai kalor. Kadar air tertinggi dihasilkan dari biobriket dengan komposisi eceng gondok 50\% sedangkan kadar air terendah dihasilkan dari biobriket dengan komposisi eceng gondok $30 \%$. Pada penelitian ini ketiga sampel memenuhi standar kadar air yang ditentukan oleh SNI 016235-2000. Namun apat disimpulkan bahwa komposisi optimum pada konsentrasi perekat $70 \%$.

Kadar abu yang terendah pada biobriket dengan komposisi perekat $70 \%$ dan nilai kalor tertinggi yang dihasilkan pada biobriket dengan komposisi perekat kotoran sapi $70 \%$ yaitu 4715 kal/gram.

Jika mengacu pada SNI 01-6235-2000, penelitian ini menghasilkan biobriket yang baik pada komposisi perekat $70 \%$.

\section{UCAPAN TERIMA KASIH}

Bersama terbitnya Jurnal ini, kami mengucapkan terimakasih kepada Kementrian Riset, Teknologi dan Pendidikan Tinggi Republik Indonesia yang telah memberi kepercayaan pada kami dengan mendanai penelitian ini melalui dana hibah Penelitian Dosen Pemula. Tahun anggaran 2019.

\section{REFERENSI}

[1] E. Elfiano, M. Natsir, and D.D. Indra, "Analisa Proksimat Briket Bioarang Campuran Limbah Ampas Tahu dan Arang Kayu", Prosiding SNTTM, vol. 14, no.
ISBN:978-602-70012-0-6, pp. 1-6, 2014.

[2] M.A. Karim., E. Ariyanto, and A. Firmansyah, "Biobriket Eceng Gondok (Eichhornia Crassipes) sebagai Bahan Bakar Energi Terbarukan", Universitas Muhammadiyah Palembang, 2014.

[3] A. Saleh, "Efisiensi Konsentrasi Perekat Tepung Tapioka Terhadap Nilai Kalor Pembakaran Pada Biobriket Batang Jagung (Zea Mays L.)", Jurnal Teknosains, vol. 7, no. 1, pp. 78-89, 2010.

[4] M.Y. Thoha and D.E. Fajrin, "Pembuatan Briket Arang dari Daun Jati dengan Sagu Aren sebagai Pengikat", Jurnal Teknik Kimia, vol. 17, no. 1, pp. 34-42, 2010.

[5] A. Katimbo, N. Kiggundu, S. Kizito, H.B. Kivumbi, and P. Tumutegyereize, "Potential of Densification of Mango Waste and Effect of Binders on Produced Briquettes", Agricultural Engineering International: CIGR Journal, vol. 16, no. 4, pp. 146-155, 2014.

[6] M. Faizal, I. Andynapratiwi, and P.D.A. Putri, "Pengaruh Komposisi Arang dan Perekat Terhadap Kualitas Biobriket dari Kayu Karet”, Jurnal Teknik Kimia, vol. 20, no. 2, pp. 36-44, 2014.

[7] G. Lu, H. Kim, J. Yuan, I. Naruse, K. Ohtake, and M. Kamide, "Experimental study on selfdesulfurization characteristics of biobriquette in combustion", Energy and Fuels, vol. 12, no. 4, pp. 689-696, 1998.

[8] A.R. Fachry, T.I. Sari, A.Y. Dipura, and J. Najamudin, "Teknik Pembuatan Briket Campuran Eceng Gondok dan Batubara sebagai Bahan Bakar Alternatif bagi Masyarakat Pedesaan", Perkemb. Ris. dan Teknol. ke-16, Jakarta. 5258, vol. 16, no. ISBN:978-979-95620-6-7, 2010.

[9] M.A. Karim, E. Ariyanto, and A. Firmansyah, "Eceng Gondok Sebagai Bahan Bakar Energi Terbarukan", Reaktor, vol. 15, no. 1, pp. 5963, 2014.

[10] G.Q. Lu, T. Toyama, H.J. Kim, I. Naruse, K. Ohtake, and M. Kamide, "Fundamental Study on Combustion Characteristics of Biobriquette", Kagaku Kogaku Ronbunshu, vol. 23, no. 3, pp. 404-412, 1997.

[11] S 01-6235-2000, "SNI 01-6235-2000", SNI 01-6235-2000, 2000.

[12] Mandasini, Sungkono, and T. Syarif, "Biobriquette Characteristics of Mixture of Coal-Biomass Solid Waste Agro", IOP Conference Series: Earth and Environmental Science, vol. 175, no. 1, pp. 012-031, 2018.

[13] H. Hayami, M. Nakamura, and K. Yoshioka, "A joint Japan-China research project for reducing pollution in China in the context of 
the Kyoto protocol Clean Development Mechanism (CDM): Case study of the desulfurdized bio-coal briquette experiments in Shenyang and Chengdu", Managerial and Decision Economics, vol. 24, no. 2-3, pp. 213229, 2003.

[14] D. Hidayat, G. Nurohman, S. Setianto, B. Mukti Wibawa, and N. Suhendi, "Uji Kinerja Burner dan Tabung Reaktor Flame Untuk Proses Spray Pyrolysis", Reaktor, vol. 17, no. 2, pp. 67-73, 2017.

[15] M. Jahiding, L. O. Ngkoimani, E. S. Hasan, Hasria, and S. Maymanah, "Analisis Priksimasi dan Nilai Kalor Bioarang Sekam Padi sebagai Bahan Baku Briket Hybrid," Jurnal Aplikasi Fisika, vol. 7, no. 2, pp. 77-83, 2011.
[16] A. Triantoro, A. Mustofa, K. Kartini, and A. Hanafi, "Studi Analisa Kualitas Biobriket Campuran Bottom Ash Batubara dan Onggok Tepung Tapioka Menggunakan Karbonisasi,” Jurnal Fisika FLUX, vol. 1, no. 1, pp. 54-60, 2019.

[17] W. Zhou, R. Apkarian, Z. L. Wang, and D. Joy, "Fundamentals of scanning electron microscopy (SEM)," Scanning Microscopy for Nanotechnology: Techniques and Applications, pp. 1-40, 2007.

[18] A. Sujatno, R. Salam, A. Dimyati, and Bandriyana, "Studi Scanning Electron Microscopy (SEM) untuk Karakterisasi Proses Oxidasi Paduan Zirkonium", Jurnal Forum Nuklir, vol. 9, no. 2, pp. 44-50, 2015. 